\title{
Diseñando la Nación: Jóvenes becados por el gobierno a Europa, su contribución en la construcción del Chile de inicios del siglo XX
}

\section{Designing the Nation: Young people awarded with scholarship by the government to Europe, its contribution in the construction of Chile during the early 20th century}

\author{
Tatiana Jiménez Bustos \\ Université Paris I - Pántheon Sorbonne \\ Tatiana.jimenez.b@gmail.com
}

\begin{abstract}
Resumen
El decreto del 31 de Octubre de 1888 marcó un antes y un después en lo referido a la subvención educativa para jóvenes chilenos en Europa, pues es a partir de esta norma jurídica que se oficializó este tema mediante el reglamento sobre el envío de estudiantes a perfeccionarse en el extranjero, con el objetivo que, gracias a los conocimientos adquiridos, pudiesen a su regreso contribuir a la conformación de una nación más fortalecida.

Este artículo da cuenta de todo el proceso de pensiones desde sus orígenes a mediados del siglo XIX, hasta inicios del siglo XX. Se pone especial atención en cómo las políticas públicas que se fueron implementando con el paso de los años, bajo la influencia de diferentes factores; tanto de las decisiones gubernamentales, del ideario de los intelectuales, de las modas de la oligarquía y de la experiencia adquiridas por los primeros pensionados, contribuyeron al establecimiento de un sistema de base para la subvención becaria en el país.

Lo precedente, generó aportes de conocimientos específicos en diferentes áreas del quehacer profesional, tanto jurídicas, artísticas como científicas, que propiciaron hacer de Chile, de los inicios del siglo XX una nación consolidada.
\end{abstract}

\section{Palabras Claves}

Beca de estudios, Gobierno de Chile, Europa, Jóvenes estudiantes, Siglo XIX.

\begin{abstract}
The decree of October $31^{\text {st }}, 1888$, was a turning point for the educational subsidy given to young Chileans in Europe, because from this legal standard on, this issue was made official with a regulation of students going for advanced education abroad, with the objective of thanks to the knowledge acquired, they could, on their return, contribute to the formation of a stronger nation.

This article accounts for complete scholarship process, from its origins in the midnineteenth century until the early twentieth century. Special attention was focused on how public policies that were implemented over the years, under the influence of different factors; both governmental decisions, as well as the ideas of the intellectuals, the oligarchy

Esta obra está sujeta a la Licencia Reconocimiento-NoComercial-CompartirIgual 4.0 Internacional de Creative Commons. http://creativecommons.org/licenses/by-nc-sa/4.0/




\section{Tatiana Jiménez Bustos}

fashions and the experience acquired by the first scholarship holders, contributed to the creation of a basic system for the scholarship subsidy in the country.

Before mentioned meant specific knowledge contributions in different areas of professional work, both legal, artistic and scientific, which contributed for Chile, of the early twentieth century, to be a consolidated nation.

\section{Keywords}

Scholarships, Chilean Government, Europe, Young students, 19th century

Con el propósito de dilucidar el proceso de conformación de las becas gubernamentales de Chile hacia extranjero, es que este artículo consta de las siguientes partes: primeramente y como marco introductorio, se expone cómo la educación en el país y más específicamente la necesidad del refuerzo de la misma, fue crucial a la hora de la puesta en marcha de las pensiones. En segundo lugar, se presenta el objetivo de los envíos, como fue capitalizar en nuevos conocimientos a profesionales nacionales en el extranjero. En tercer lugar, dar cuenta de la normativa legal inherente al sistema. Como cuarto punto, se presentan las contribuciones de los pensionados a su regreso al país, y por ultimo las conclusiones.

\section{La educación constituye un pilar fundamental de la nueva nación que comenzaba a constituirse}

En materia de subsidios gubernamentales para la realización de estudios de especialización en el extranjero, el siglo XIX significó para Chile la realización formal, de un esfuerzo que se venía gestando desde las primeras décadas de la República. Dicha política pública formó parte del proyecto general del Estado de hacer de Chile una nación consolidada, teniendo como objetivo saldar el vacío de profesionales nacionales con las competencias necesarias que pudiesen ejercer en cargos públicos, que hasta entonces, sólo habían sido dirigidos por extranjeros.

La puesta en marcha de dicho propósito, vale decir, las políticas públicas que otorgaron financiamientos para la realización de estudios en el extranjero, se pudo constituir gracias a que Chile hacia la década de 1830 presentaba un escenario de tranquilidad y de orden público, inexistente en la región, lo que favoreció la llegada de intelectuales, jurisconsultos y científicos extranjeros provenientes de Europa y América, mucho antes de la fundación de la Universidad de Chile. Así Andrés Bello, José Joaquín de Mora, Ignacio Domeyko, Claudio Gay, Rodulfo Phillipi o el mismo Domingo Faustino Sarmiento, entre otros, fueron personajes ${ }^{1}$ fundamentales a la hora de idear y construir las bases del sistema educativo. Igualmente, fue crucial que las autoridades de la época fueran receptivos a las observaciones e inquietudes de

\footnotetext{
${ }^{1}$ Muchos de ellos fueron contratados para impartir clases en escuelas, liceos y en el Instituto Nacional, siendo incorporados posteriormente a la Universidad de Chile.
} 


\section{Diseñando la Nación: Jóvenes becados por el gobierno a Europa, su contribución en la construcción del Chile de inicios del siglo XX}

estos intelectuales, situación que se fue plasmando en diferentes disposiciones legales para la realización de estas pensiones de estudio.

Un ejemplo de la implicancia de estos intelectuales, en lo relativo a las subvenciones fue la figura de Claudio $\mathrm{Gay}^{2}$, a quien en el período en que se encontraba en imprenta su obra la Historia Física y Política de Chile en París, el Ministerio de Instrucción Pública le encomendó la misión de dirigir, en representación del Estado, la educación de tres jóvenes: Manuel Osorio, Teodisio Cuadros y Antonio Cavada, dándole total libertad de alterar las instrucciones que se le dieran para los estudios de los mismos, si juzgase necesario y de hacerles entender que como pensionados del gobierno a la menor falta cometida, serían restituidos al país ${ }^{3}$.

La inminente necesidad de estos envíos, se dieron a conocer como política pública por primera vez en las Memorias, que el Ministro de Estado Manuel Montt del Departamento de Justicia, Culto e Instrucción Pública, presentase al Congreso Nacional en el año 1841, diciendo:

Sería sin duda conveniente enviar a Europa dos o tres jóvenes sobresalientes para que completen allí su instrucción... .... El Gobierno prestará una atención preferente a esta medida, que ha de ejercer una influencia benéfica en el fomento de nuestra industria minera4.

Continuando con la misma idea en la Memoria del año 1842, el Ministro Manuel Montt, declara:

El Gobierno para proveer esta necesidad, ha resuelto enviar a Europa tres jóvenes de los que con más provecho han cursado la química y mineralogía en el Colegio de Coquimbo, a fin de que se perfeccionen en estas ciencias y vengan a propagar después entre nosotros conocimientos tan útiles ${ }^{5}$.

Si bien, el envío de estos tres estudiantes se realizó por manifiesto público, las fuentes indican que el primer envío se llevó a cabo un año antes, ocasión en que

\footnotetext{
${ }^{2}$ El naturalista de origen francés Claudio Gay fue contratado por el gobierno chileno en 1830 para explorar, reconocer y estudiar el territorio chileno y sus recursos, terminó preparando la primera cartografía de carácter nacional del país. El quehacer geográfico de Gay es apreciado en el contexto de las relaciones entre ciencia y poder, y sus mapas interpretados como un instrumento esencial de la administración estatal en cuanto herramienta para la integración territorial y el ejercicio de la soberanía, En Rafael Sagredo. "Geografía y nación. Claudio Gay y la primera representación cartográfica de Chile". Estudios Geográficos. Vol. LXX, № 266, Enero-junio. Madrid, 2009, pp. 231-267. ${ }^{3}$ Ramón Irarrázaval. Correspondencia dirigida al Encargado de Negocios de Chile en Francia. Santiago, 10 de Abril de 1844. En Archivo Nacional de Chile (ANC), Legación de Chile en Francia y Gran Bretaña 1829-1877. Vol. 11.

4 Manuel Montt. "Memoria que el Ministro de Estado en el departamento de Justicia Culto e Instrucción Pública presenta al Congreso Nacional. Año de 1841", en Documentos Parlamentarios. Discursos de apertura en las secciones del Congreso, i Memorias ministeriales correspondientes a la administración Prieto. (1831-1841). T.I. Santiago, Imprenta del Ferrocarril, 1858, p. 231.

5 Manuel Montt. Memoria presentada al Congreso Nacional en 1842 por el Ministro del Despacho de Justicia Culto e Instrucción Pública. Santiago, Imprenta y Litografia del Estado, 1842, p.26.

Los tres jóvenes enviados a Europa al año siguiente, fueron Antonio Alfonso Cavada, Manuel Antonio Osorio y Teodosio Cuadros.
} 


\section{Tatiana Jiménez Bustos}

se envió al joven Agustín Olavarrieta ${ }^{6}$ a especializarse en el área de ingeniería militar a Europa y que conforme a la correspondencia entre el Ministro Manuel Montt y el naturalista Claudio Gay, éste último de igual manera habría realizado el seguimiento del quehacer académico del becado.

Por su parte, en lo referido a la necesidad de implementación de pensiones manifestadas en los discursos presidenciales, el Presidente Manuel Bulnes, desde su óptica de valoración por el área militar en 1844 expresaría:

...Me es grato repetir lo que en ocasiones anteriores os he dicho sobre el buen espíritu i bien regulada disciplina del Ejército i de las Guardias... ... Academia militar me inspira lisonjeras esperanzas?.

Introduciendo así la razón de su decisión a la hora de poner en marcha de manera "grupal" los subsidios optando por oficiales militares; en 1847 enviaría a un grupo de 13 jóvenes pertenecientes al área castrense a realizar estudios de especialización a la Escuela de Puentes y Caminos de Paris, señalando:

La escuela militar, plantel precioso, que desde sus primeros dias ha hecho concebir las mas lisonjeras esperanzas, modelo de réjimen i disciplina que yo desearía ver imitado en todos los establecimientos de educacion, empieza ya a retribuir a la patria las moderadas sumas que en ella se invierten. Diez i seis de sus jóvenes alumnos manifestaron a fines del año último distinguidas aptitudes para el servicio de oficiales; i trece de ellos fueron enviados a Francia para que completando sus estudios en las escuelas de aplicacion práctica pudiesen a su vuelta hacerse mas señaladamente útiles en los cuerpos facultativos del ejército ${ }^{8}$.

Si bien, entre los años 1848 y 1885 no hubo discursos presidenciales que dieran cuenta de los envíos, se realizaron igualmente cerca de una docena, principalmente en el área artística. Envíos de la talla de los artistas Nicanor Plaza, Cosme San Martín, Alfredo Valenzuela Puelma, entre otros, quienes formarían parte, a su regreso, de la recién inaugurada Escuela de Bellas Artes en 1848.

A partir de 1886 los envíos se incrementan diversificando sus áreas de estudios, es así como el presidente de la República, Domingo Santa María en su

\footnotetext{
${ }^{6}$ El joven Agustín Olavarrieta Wassermayer hizo estudios de matemáticas en la Escuela Militar y en 1843 fue enviado por el Gobierno, con el grado de teniente de ingenieros militares, a perfeccionar sus estudios en Europa De regreso al país en 1847, fue ascendido a sargento mayor de ingenieros militares. Su memoria sobre la Artillería de Campaña y de Montaña, le mereció la distinción de ser designado miembro de la Facultad de Ciencias Físicas y Matemáticas

7 Manuel Bulnes. "Discurso que el presidente de la República dirije al Congreso nacional. Año de 1844", en Documentos Parlamentarios. Discursos de apertura en las sesiones del Congreso, i, Memorias ministeriales correspondientes al Pmer. Quinquenio de la administración de Bulnes (1842-1846). T.II. Santiago, Imprenta del Ferrocarril, 1858, p. 216.

${ }^{8}$ Manuel Bulnes. "Discurso que el presidente de la República en la apertura de las cámaras legislativas de 1847", en Documentos Parlamentarios. Discursos de apertura correspondiente al segundo quinquenio de la administración de Bulnes. (1847-1851). T.III. Santiago, Imprenta del Ferrocarril, 1858, p. 5.
} 


\section{Diseñando la Nación: Jóvenes becados por el gobierno a Europa, su contribución en la construcción del Chile de inicios del siglo XX}

discurso ante la cámara de Senadores en 1885 hace mención a este respecto, dando a conocer que ingenieros de la marina se especializarían en Europa:

Una parte de nuestros marinos hace hoi en Europa especiales estudios, $i$ algunos de ellos deben navegar en las marinas estranjeras para habilitarse, de este modo, de mejores i mas acabados conocimientos, Los efes, ayudados de competentes injenieros, habrán de instruir al Gobierno de cuál es la naturaleza del nuevo buque que habrá de construirse, atendidas las mejoras que en ellos ha introducido la ciencia náutica i las necesidades jenerales de nuestra Armada9.

El incremento de los envíos se pudo realizar gracias al auge económico desarrollado por entonces en el país. Entre muchos factores incidentes en este superávit, destaca el denominado "Ciclo del Salitre" como fuerte generador de dicho crecimiento. Según ciertos autores, el salitre fue el motor de la economía del país por medio siglo (1883-1929) ${ }^{10}$.

El aumento y la variedad de becas quedaría de manifiesto en discurso Presidencial emitido por don Germán Riesco en 190511, quién señala:

Perfeccionando sus estudios se hallan en Europa dos alumnos del Instituto Agricola, dos injenieros agrónomos i veinte alumnos de la Escuela de Artes i Oficios.

La nueva nación que comenzaba a construirse, tuvo entre sus planes, hacer de un Chile una Nación "moderna"12. No obstante se trató de una decisión política, como los archivos así lo indican que, en lo cultural abarcó desde las artes a las ciencias sociales y desde la poesía a la arquitectura. De igual manera, el referido propósito fue asumido vivamente por la población, particularmente por la elite, la que de acuerdo a la moda imperante, incitó al "afrancesamiento" de la sociedad en todas sus áreas.

En la búsqueda del perfeccionamiento en el extranjero, se produjeron diversas gestiones tendientes a facilitar la permanencia temporal de los jóvenes en un primer tiempo por medio de decretos y correspondencia Consular, asegurando así del bienestar de los jóvenes estudiantes. Con el paso de los años, dicho propósito lo expresaría el economista, profesor y político Daniel Martner, en el 9o Congreso

\footnotetext{
${ }^{9}$ Chile, Congreso Nacional, Senado. Sesiones ordinarias de la cámara de Senadores de 1885. Santiago de Chile, La Cámara. 1885, p.8.

${ }^{10}$ Es necesario considerar, para la comprensión de este fenómeno, que el desierto de Atacama es uno de los pocos lugares en el mundo donde se produce el nitrato de sodio de forma abundante y que no fue hasta la primera década del siglo XX que se hizo la primera producción de salitre sintético en Alemania. Este preciado recurso natural, el Salitre (Nitrato de Sodio), fue considerado estratégico en los mercados internacionales, ya que poseía dos fundamentales funciones. Por una parte, se trataba de abono para la agricultura y por otra, materia prima para la elaboración de la pólvora.

${ }^{11}$ Germán Riesco. Mensaje leído por S.E. el Presidente de la Repúblicas en la apertura de las sesiones ordinarias del Congreso Nacional. Santiago de Chile, Imprenta i Encuadernación Barcelona, 1905, p.32.

${ }^{12}$ El concepto "moderno" se entenderá básicamente como lo "Perteneciente o relativo al tiempo de quien habla o a una época reciente", en otras palabras lo que "sigue las últimas tendencias o adelantos" para su época.", vale decir en este caso de principios del siglo XX.
} 


\section{Tatiana Jiménez Bustos}

Internacional de Enseñanza Comercial, realizado en Viena desde el 11 al 16 de septiembre de 1910, aseverando que el objetivo del envío al extranjero consistía en que los alumnos pudiesen ensanchar su horizonte científico, económico y profesional.

En lo referido al área urbana, el proyecto modernizador siguió los parámetros de la ciudad de Paris, abarcando tanto mejoras en obras públicas como en el embellecimiento de edificios existentes y de espacios públicos, con el propósito de acercarse a la "ciudad de las ciudades"13, tal y como la denominara Vicuña Subercaseaux en sus cartas publicadas en el diario El Mercurio de fin de siglo XIX, cuya divulgación por este medio impreso promocionó este modelo a seguir hacia inicios del siglo XX.

Particularmente, en lo que a obras públicas se refiere, es a partir de la creación del Ministerio de Industria i Obras Públicas en 1887 y de la Dirección de Obras Públicas en 1888, es que el avance hacia la modernización del Estado comienza a establecerse. Por una parte, surgen innumerables obras que dejan evidencias físicas de dicha nueva etapa, como fueron los numerosos trabajos en transporte y comunicación; vale decir, vías férreas, trazados de tranvías, correos y telégrafos, a lo largo de gran parte del territorio ${ }^{14}$. Por otra parte, el avance en infraestructuras como el mejoramiento de caminos, puentes y viaductos; la creación de más de diez puertos, aduanas; establecimientos educacionales, hospitalarios y penales, etc.

A este respecto cabe señalar que, con ocasión de la celebración del Centenario de la Independencia de Chile en 1910, muchos de los proyectos de obras públicas se adjudican realizados para dicha conmemoración. Las obras realizados para celebrar dicho aniversario, consistieron principalmente en esculturas y monumentos, es decir, obras de hermosamiento de la ciudad ${ }^{15}$. Las obras públicas de importancia, como se ha dicho, ya se venían proyectando y construyendo desde mucho antes, abarcando la segunda mitad del siglo XIX.

En lo referido a la educación, en el año 1837 se implementó el Plan general de educación pública, lo que provocó la creación de instituciones educativas en todo el país. De esta forma, se da origen a la fundación de organismos tales como escuelas públicas, universidades y museos. Nacen entonces, en 1842 la Escuela Normal y la Universidad de Chile, en 1848 la Academia de Bellas Artes, en 1849 la Escuela de Artes y Oficios, entre otras.

Adscrito a lo anterior, una de las disciplinas especialmente valoradas en esta época fue la enseñanza del dibujo. Esta herramienta considerada como la base de todas las profesiones, tal y como manifestara el destacado educador y político Manuel de Salas, esta disciplina entregaba "Lecciones de Virtud" a quien la

\footnotetext{
${ }^{13}$ Benjamín Vicuña. La ciudad de las ciudades: correspondencias de Paris. Santiago de Chile, Sociedad Imprenta y Litografía Universo, 1905, p. 21.

14 Abarcando unos 2/3 del largo de Chile continental, $3078 \mathrm{~km}$ de un total de $4400 \mathrm{~km}$. Vale decir una vía férrea directa entre Barcelona a Moscú.

${ }^{15}$ Macarena Ibarra. "El Centenario: ¿Un mito urbano?. Santiago de Chile 1887-1910". Bicentenario. Revista de Historia de Chile y América. Vol. IV, №1. Santiago de Chile, 2005, pp.141-162.
} 


\section{Diseñando la Nación: Jóvenes becados por el gobierno a Europa, su contribución en la construcción del Chile de inicios del siglo XX}

dominara. Si se quería fomentar la industria y el comercio era necesario establecer la enseñanza de la aritmética, la geometría y el dibujo ${ }^{16}$.

Por consiguiente, el dibujo no sólo era entendido meramente como un instrumento técnico sino más bien, como el medio primordial a través del cual, se inmortalizaría y reforzaría la construcción de la nueva Nación. Dicho de otro modo, en el contexto general de la génesis de las construcciones de nacionalidades en Iberoamérica, tuvo el arte un papel fundamental como arma emancipadora, la que en manos de las clases dirigentes, se convirtió en una herramienta eficaz de persuasión ${ }^{17}$, de control de opinión pública y por ende de interpretación de los personajes icónicos, de las tradiciones, de sus monumentos y de los hitos históricos ${ }^{18}$.

\section{Dibujar la República: crear capital humano en la construcción de la Nación.}

El Gobierno a la hora de poner en marcha la entrega de becas para estudios en el extranjero decidió que, no sólo fueran entregadas a profesionales de la educación, de la ingeniería, de la medicina y de las leyes, sino que al mismo tiempo, a alumnos de la Academia de Bellas Artes en su calidad de pintores, escultores y arquitectos. Dando cuenta del propósito de ir representando la reciente República mediante el dominio del dibujo en la construcción de la misma.

Los beneficiarios, si bien pertenecían a todas las áreas académicas y la selección se basó democráticamente en su buen rendimiento educacional, los orígenes sociales de éstos, eran más bien elevados. Se trataba de estudiantes que en su mayoría, estaban a punto o ya finalizaron sus carreras, cuyos estudios en el extranjero buscaban una especialización adecuada para conformar el capital humano que necesitaba el país.

Como parte de las implementaciones de modernización del país, el gobierno de Chile, desde mediados del siglo XIX envía a jóvenes de diferentes disciplinas, en condición de "pensionados", como se les llamaba en aquella época, a realizar estudios a diversos países de Europa, en su mayoría Francia, con el propósito que a su regreso, contribuyeran al pro avance del país gracias a los conocimientos adquiridos y así contrarrestar el vacío en materia de mano de obra calificada

\footnotetext{
16 Miguel Amunátegui. Don Manuel de Salas. Santiago de Chile, Imprenta Nacional, 1895, p. 69.

17 Esta preciada herramienta aparte de ser fundamental, fue transversal a diferentes disciplinas, en tanto que permitió plasmar en imágenes las nuevas naciones desde la mirada de quehaceres diversos. Así, disciplinas como la geografía, la pintura, la escultura, la botánica, la arquitectura o la ingeniería, las usarían en mapas, cuadros, esculturas, fichas, grabados, planos, etc. Vale decir manifestaciones desde: las artes visuales hasta las representaciones gráficas.

18 Rodrigo Gutiérrez. "El papel de las artes en la construcción de las identidades nacionales en Iberoamérica". Historia Mexicana, El Colegio de México. Vol. LIII, № 2, Oct. - Dec., México, 2003, pp. 341390.
} 


\section{Tatiana Jiménez Bustos}

nacional de la época, tal y como lo señala en el decreto Ministerial de 1845 que adjudicó la pensión a Don Manuel Aldunate ${ }^{19}$ :

... Teniendo en consideracion:

$1^{\circ}$ La falta absoluta de arquitectos que hai en el pais para la direccion de los edificios públicos.

$2^{\circ}$ Que no podrán formarse hombres intelijentes en este ramo sin que vayan a completar sus estudios de aplicacion a Europa,...

A la luz de los archivos existentes, se puede deducir que la implementación de las Pensiones fue un proceso paulatino y diversificado en las áreas de conocimiento que se precisaban. Es así como, en un principio los envíos fueron realizados con el propósito de reforzar el recién creado Cuerpo de Ingenieros Civiles 1843 y así producir infraestructura y personal capacitado para la protección militar de la joven Republica. En sólo 5 años (1843-1847) fue enviado un grupo de estudiantes, en su mayoría ingenieros militares. Se envía al ingeniero Don Agustín Olavarrieta en 1843 y un año más tarde a los ingenieros en minas Antonio Cavada, Teodosio Cuadros y Manuel Osorio. Al finalizar la dirección a cargo de don Claudio Gay, de estos tres jóvenes enviados a estudiar, expresaría ${ }^{20}$ :

Los tres jóvenes que el Supremo Gobierno hizo poner bajo mi dirección han concluido sus estudios con gran satisfacción de sus profesores, muy dispuestos a darles los mejores certificados de aplicación y capacidad. Creo que el Supremo Gobierno tendrá que felicitarse de haber mandado estos jóvenes a Europa...

Ciertamente, fue alabada la idea de enviar a estos jóvenes por el intelectual Gay, a pesar de que su asesoría le pareció un trabajo arduo como expresaría más tarde en relación a la burocracia generada por Ministro en Paris ${ }^{21}$.

De lo anteriormente citado, en 1847 se envió a un grupo de 13 jóvenes ingenieros oficiales militares a la escuela de Puentes y Calzadas de Paris. La única profesión discordante entre los ingenieros fue la del pensionado arquitecto Manuel Aldunate efectuada en 1845.

En otras palabras a 1847, los envíos en el área de la ingeniería suman 17 profesionales. A posteriori los envíos en esta área se hicieron más distanciados y puntuales ante una menor demanda.

En concordancia a las fuentes existentes, entre los años 1863 y 1887 los envíos fueron mínimos y circunscritos al área artística; pintores, escultores y

\footnotetext{
19 Manuel Montt. Correspondencia de dirigida al Encargado de Negocios del Gobierno de Chile cerca del de Francia. Santiago, 27 de Noviembre de 1845. En Archivo Nacional de Chile, Legación de Chile en Francia y Gran Bretaña 1829-1877. Vol. 11.

Se refiere a la pensión de estudios de arquitectura en Francia al señor Manuel Aldunate.

${ }^{20}$ Claudio Gay. Correspondencia de Claudio Gay. Santiago de Chile, Ediciones de la Biblioteca Nacional, 1962, p. 99.

${ }^{21}$ Ibidem.
} 


\section{Diseñando la Nación: Jóvenes becados por el gobierno a Europa, su contribución en la construcción del Chile de inicios del siglo XX}

músicos. A partir de fin de la década de los 80 es que los envíos se amplían a otras áreas del conocimiento.

En virtud del auge económico anteriormente mencionado, que abarcó desde el fin del siglo XIX hasta principios del XX, el envío de pensionados se incrementó notoriamente durante en el gobierno de José Manuel Balmaceda (1886-1891). Las fuentes disponibles hablan de una treintena de jóvenes, los que fueron enviados a realizar estudios en Europa en pequeños grupos desde 11 de feb 1886 hasta 10 de dic 1891. Según el informe anual de 1892 de la Legación de Chile en Francia, el Ministro Augusto Matte con fecha $1^{\circ}$ de febrero de 1893, como parte de la cuenta de Instrucción Pública, indicaba en oficio con fecha 12 de julio de 1892 se notificó a esta legación la suspensión del pago de pensiones desde el 31 de Diciembre del año en curso $^{22}$, a todos los pensionistas que se encuentran en Europa, con excepción de seis que cursan medicina. A la fecha de término de dicho informe, hasta lo que se puede evidenciar, las profesiones becadas fueron de ingeniería, arquitectura, medicina, educación, leyes, pintura, escultura y música.

\section{Reglamentación, hacia la conformación de un sistema de becas de estudios en el extranjero.}

Por su parte, si se analiza la reglamentación de las pensiones en relación al contenido de sus contratos, desde sus inicios hasta la aparición de las bases oficiales de postulación, vale decir entre los años 1845 y 191123, el diseño del reglamento fue básicamente el mismo tanto en lo financiero como en lo burocrático.

En lo referido al financiamiento, por ejemplo, tanto en el aporte en pasajes como en la manutención anual se reajustaron en función del crecimiento del país y se especificaron de la siguiente manera:

\section{... Los gastos de transporte en la navegacion serán costeados por el gobierno en su ida i vuelta, i gozará ademas, de la asignacion de seiscientos pesos anuales. \\ ... Si por su culpa no cumpliere esta obligacion, será obligado a restituir con los intereses. \\ ... permanecerá en Paris en donde debe hacer sus estudios bajo el cuidado $i$ vijilancia del Encargado de Negocios de la Republica; quien dará periódicamente de la conducta i aprovechamiento que tuviere el citado.}

Asimismo, la retribución financiera en caso de incumplimiento de deberes fue condición sine qua non, sólo en 1911 hubo salvedad al este respecto; pudo ser eximida por decreto presidencial, en caso de pobreza.

\footnotetext{
${ }^{22}$ Suspensión debido al recorte financiero estatal con motivo de la Revolución de 1891 vivida en Chile.

${ }^{23}$ Período correspondiente entre 1845 año de Adjudicación de Pensión de estudios en el Europa a Don Manuel Aldunate, Véase en: Manuel Montt. Correspondencia de dirigida al Encarg..., Op. Cit. (caso que sirve de ejemplo para demostrar la subvención de los primeros tres años) y 1911, año en que se crea la primera reglamentación oficial, véase en: Chile, Decreto oำ133 (1911). Reglamente sobre Becas en el extranjero. Diario Oficial de la República de Chile.
} 


\section{Tatiana Jiménez Bustos}

Sin embargo, en materia administrativa se fue modificando en función a la experiencia práctica de la entrega de subvenciones con el paso de los años. Muestra de ello fue que la duración máxima de estadía de estudios que en 1845 fue de cuatro años, la que se aumentó a cinco ${ }^{24}$ en 1886.

Ahora bien, si nos enfocamos en el primer reglamento oficial dictado por Decreto del 31 de octubre de 1888: llamado Reglamento de "Pensionados en Europa", significó el antes y después de una larga etapa que desde la década de 1840 hasta los inicios del siglo XX.

Producto de los primeros envíos de estudiantes de ingeniería y las artes, se fueron perfeccionando los procedimientos a seguir, como por ejemplo la determinación cantidad de estudiantes pensionados por área. Todo lo anterior, se pudo hacer efectivo gracias al financiamiento disponible de la positiva economía de la época.

Así, el acuerdo celebrado por el Consejo de Instrucción Pública el 24 de octubre de $1888^{25}$ determinó en términos generales el objetivo y la cuantía general de pensionados para cada área académica, diciendo:

... Con el objeto de perfeccionar los estudios que hubiesen hecho en la Universidad, o con el de adquirir los conocimientos especiales que el Consejo de Instrucción Pública designe, se sostendrán en Europa, por cuenta del Estado, hasta tres alumnos del curso de leyes y ciencias políticas, hasta cuatro del curso de bellas artes, hasta seis del curso de medicina y farmacia, y hasta igual número del de ciencias físicas y matemáticas.

Contempló de igual forma que, el Consejo de Instrucción pública establecería cuáles serían los cursos a seguir, el tiempo de duración según cada dominio, estableciendo:

... $1^{\circ}$ El ramo o ramos de estudio a que deba dedicarse especialmente el alumno que aspire a ser pensionado;

$2^{\circ}$ Las universidades o establecimientos de instrucción en que deba hacerse el estudio; $y$

$3^{\circ}$ El tiempo que este estudio debe durar.

El tiempo no podrá exceder, sino en casos especiales, calificados por el Consejo, de tres años, para los alumnos de leyes y ciencias políticas; $y$ de cinco, para los alumnos de los demás cursos.

Podrá el Consejo determinar, del mismo modo, que los pensionados que hayan de dedicarse al estudio de medicina y farmacia, o de ciencias físicas y matemáticas deben obligarse a obtener el respectivo título o grado que se conceda en el país o Universidad que se le designe para hacer sus estudios.

\footnotetext{
${ }^{24}$ José Miguel Blanco, "El envío de los pensionistas a Europa (al Sr. Ministro del Culto)". El Taller Ilustrado, periódico artístico y literario, № 59, Año II, Santiago, 1886. pp. 3-4.

En el área de las Bellas Artes fue Blanco quién contribuyó en extender tanto la estadía a 5 años como la edad límite, edad que podría sobrepasar los 25 años, argumentando la necesidad de mayor "madurez" de los estudiantes.

${ }^{25}$ Chile. Decreto Reglamento de Pensionados en Europa. Santiago de Chile. Consejo de Instrucción Pública. 1888.
} 


\title{
Diseñando la Nación: Jóvenes becados por el gobierno a Europa, su contribución en la construcción del Chile de inicios del siglo XX
}

En lo referido a la designación de los alumnos para optar a pensiones deberían citarse a concurso por el término de un mes, reuniendo las siguientes condiciones:
1 a Tener de veinte a veinticinco años.
$2^{a}$ Haber obtenido el grado de licenciado en la respectiva Facultad, entendiéndose que esta condición no se exigirá a los alumnos de bellas artes.
$3^{a}$-Haber hecho sus estudios universitarios con regularidad, en el orden y en el tiempo designado por los reglamentos; $y$
4⿳亠丷厂 Haber obtenido premios o menciones honrosas en los cursos universitarios.

El procedimiento de selección estableció las condiciones de postulación, el jurado y el proceder de los mismos, cuyo tribunal fue conformado por el rector de la Universidad y todos los profesores de la Facultad respectiva al área de estudios del postulante, estableciendo:

\begin{abstract}
... Art. 5o. Los que se crean con derecho a ser pensionados se presentarán al rector de la Universidad acompañando los antecedentes y documentos que estimen convenientes.

Concluido el plazo de la citación, el rector convocará para un día y hora determinados, a los miembros del jurado que debe hacer la elección.

El jurado se compondrá del rector de la Universidad y de todos los profesores de la Facultad respectiva en cuyas clases hayan sido alumnos los aspirantes. Si alguno o algunos de estos profesores hubieren dejado de serlo, se reintegrará el jurado con los que les hayan reemplazado...
\end{abstract}

El pensionado deberá garantizar su estadía en sus estudios, de la siguiente manera:

... el pensionado deberá acreditar cada dos meses, ante el respectivo agente diplomático, la regularidad de su asistencia a los cursos respectivos por medio de certificados expedidos por el jefe del establecimiento en que haga sus estudios o de los profesores a cuyas clases estuviere obligado a asistir.

Cuando sin motivo justificado, ante el mismo agente diplomático no se presentaren los certificados correspondientes, se suspenderá el pago de la pensión, y transcurridos cuatro meses sin que estos certificados vuelvan a presentarse, cesará todo derecho a dicha pensión. ... ... Todo alumno pensionado deberá remitir anualmente al Ministerio de Instrucción Pública una memoria original sobre la materia objeto de sus estudios.

Por último, ante el incumplimiento de las obligaciones del pensionado, éste debería:

... El alumno que no cumpliere con alguna de las obligaciones que en conformidad a este reglamento se le impongan al ser enviado a Europa, 


\section{Tatiana Jiménez Bustos}

quedará obligado a restituir las pensiones que hubiere percibido y lo que se hubiere gastado en su pasaje, debiendo para este efecto, antes de emprender su viaje, rendir una fianza a satisfacción del Tribunal de Cuentas.

El reglamento de 1888 abarcó ampliamente los derechos y deberes de los pensionados, dando cuenta de que a partir de ese momento el proyecto estatal de las subvenciones se harían con mayor regularidad.

\section{Contribuciones de los jóvenes especializados en Europa a la nación.}

La preocupación de Claudio Gay sobre cuáles serían los proyectos futuros de los jóvenes especializados bajo su dirección, al regreso de éstos, es expresada en la correspondencia al Ministro de Instrucción Pública. ${ }^{26}$ Esta fue la causa para establecer el sistema para asegurar y especificar el reembolso mediante el trabajo para el Estado que los pensionados debiesen realizar a su retorno al país.

Ciertamente, alrededor de los setenta pensionados de la época que se analiza, a su regreso hicieron alguna aportación, por mínimo que fuese al avance del país, gracias a las experiencias académicas adquiridas. Como jóvenes especializados "innovaron" de alguna manera en sus diferentes disciplinas, mejoraron el quehacer nacional en sus distintos dominios.

La contribución de los pensionados de las Bellas Artes, más específicamente de escultores y de pintores, quienes llevaron a cabo su cometido, como lo especificaba el reglamento sobre la obligación de remitir anualmente una de sus obras al Ministerio de Instrucción Pública que demostrara los avances en el arte, obras que pasaron a formar parte de exposiciones tanto nacionales como internacionales, logrando visibilidad de la nación en el mundo. En concreto, cada uno en mayor o menor medida, aumentó claramente la producción artística durante sus estudios y a posteriori de los mismos. Muestra de aquello fue la adjudicación de la primera medalla de oro para el país, en la exposición universal de 1900 para el escultor Simón González Escobar (1859-1919). De igual forma, la mayoría de los pensionados, a su regreso al país, aportaron siendo nombrados académicos y directivos de la Escuela de Bellas Artes, fortaleciendo la institución y a su alumnado. La contribución de Virginio Arias es igualmente rescatable, con su obra El Roto Chileno en 1884 premiado con medalla de oro en la Exposición Nacional de Santiago pudo traspasar fronteras, se desempeñó como profesor y recordado director de la escuela de Bellas Artes.

Los aportes de los pensionados, dentro de la instrucción pública consistió en el trabajo en todas las áreas de estudios, se desempeñaron como educadores, promoviendo así la instrucción a las nuevas generaciones en sus diferentes dominios. En particular, los profesores trabajaron en la creación y desarrollo tanto de, Escuelas públicas, Escuelas Normales, Liceos como Universidades. Un

${ }^{26}$ Claudio Gay. Correspondencia de Clau..., Op. Cit. 


\section{Diseñando la Nación: Jóvenes becados por el gobierno a Europa, su contribución en la construcción del Chile de inicios del siglo XX}

significativo aporte, fue el de don Joaquín Cabezas García profesor normalista, que fue pensionado del gobierno en 1889 , quien se perfeccionó en Suecia en trabajos manuales y gimnasia. A este profesor se le debe la puesta en marcha de la Educación física en el país. De igual modo don Ramón Álvarez, quien fue un educacionista de altos vuelos intelectuales, luego de perfeccionarse en Alemania de vuelta en Chile se le nombró visitador de escuelas en 1896, desempeñaba ese cargo en Santiago y se dedicó a introducir importantes innovaciones sobre la psicología de la intuición aplicada en la enseñanza, plasmada en publicaciones que fueron aplaudidas por la prensa.

En medicina y farmacia por su

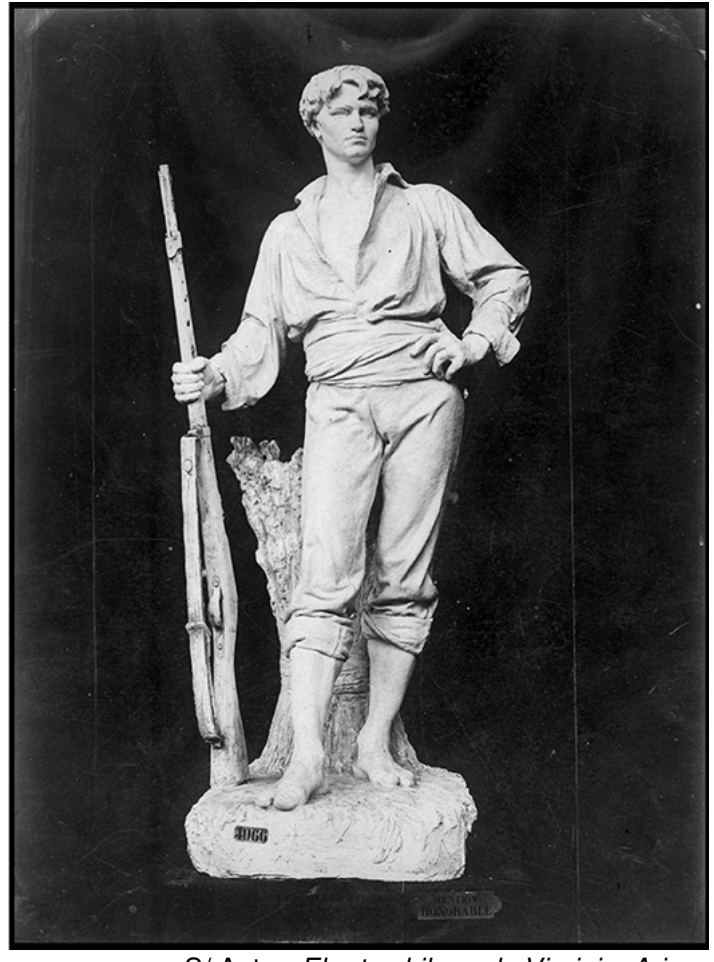

S/ Autor. El roto chileno de Virginio Arias. Negativo sobre vidrio. Catalogo Fotográfico Patrimonial, Colección Museo Histórico Nacional (MHN). PFB-2681, Chile. 1882.

parte, los estudiantes pasaron a ser activos actores en el área Pública; tanto en lo hospitalario, como en lo académico y en materia de políticas públicas sanitarias. Como es el caso de don Gregorio Amunátegui Solar pensionado en 1891. Hombre de ciencia y estadista, quién trabajó en el área médica, tanto en hospitales como realizando publicaciones de importancia y al mismo tiempo fue un político de renombre, ocupando cargos importantes como Ministro de Justicia e Instrucción pública, además de Decano de la Escuela de medicina y Rector de la Universidad de Chile. La contribución de Lucas Sierra por su parte, es digna de destacar entre diversos aportes luego de haber sido becario en 1891, su trabajo sobre procedimientos contra el cáncer, problemas de nutrición y modo de vida saludable.

En materia de ingeniería, los jóvenes especializados, hasta lo que se tiene registro, colaboraron en el área militar realizando construcciones de infraestructura como fortificaciones. Se desempeñaron además como educadores. Fue la figura de Alberto Blest Gana quien tuvo mayor protagonismo, en 1847 al ser pensionado en Francia durante cinco años. Entre sus aportes destacan la confección del primer plano de la capital, fue Intendente, Diputado y Ministro en Estados Unidos, Londres y París, lugar donde permaneció durante 20 años. Igualmente fue un renombrado hombre de letras, ha sido considerado como el creador de la novela en Chile, produjo novelas como Martin Rivas, Los Trasplantados, El ideal de una calavera, La Reconquista, etc. En las que se puede reconocer su valioso aporte a la construcción de un imaginario de la Nación de la época. 


\section{Tatiana Jiménez Bustos}

HIjinio Gonzalez Pino, por su parte, fue un ejemplo en el área de obras civiles. Ingeniero de la Universidad de Chile, nombrado pensionado de gobierno de Chile el 8 de noviembre de 1887. Ya en Francia, a los 26 años, estudia en la Escuela de Puentes y Caminos de Paris, donde figura inscrito como Alumno Externo en la promoción 1889, admitido en su calidad de funcionario extranjero ${ }^{27}$ según decisión ministerial de agosto del mismo año, especializándose en construcción de puertos. Su espíritu progresista, lo llevó a interesarse en diversos temas e incluso alejados de

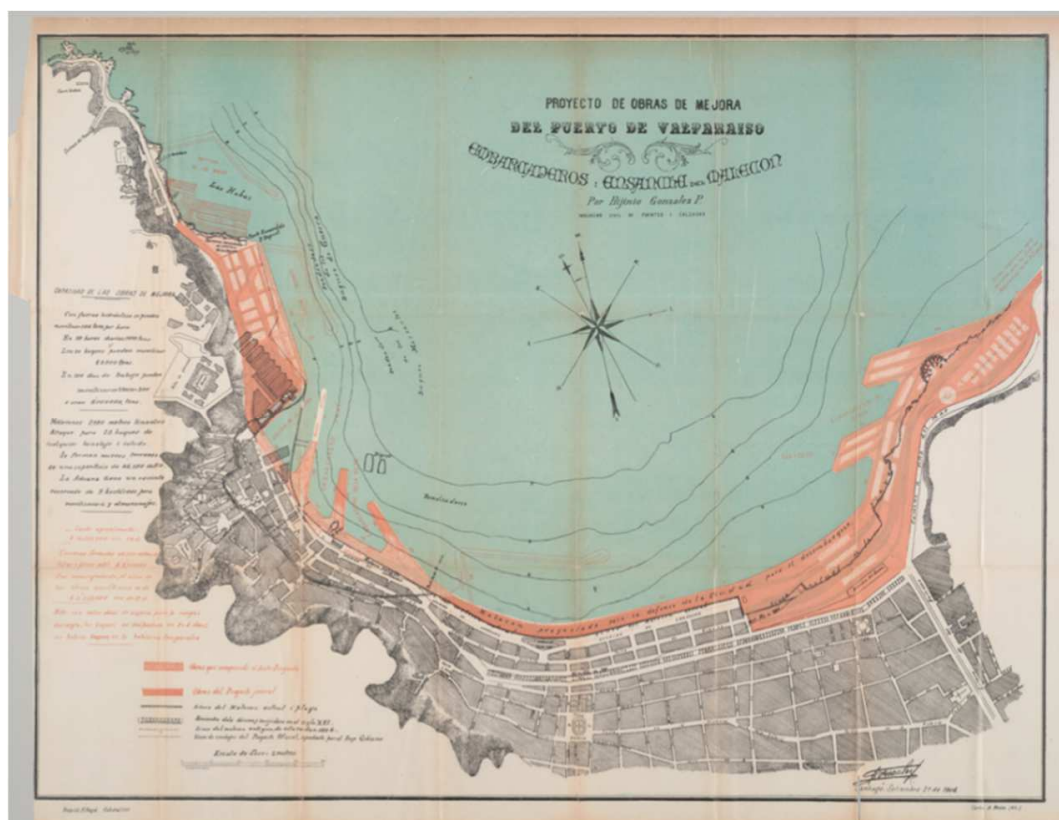

Hijinio Gonzalez. "Proyecto de obras de mejora del puerto de Valparaiso embarcadero i ensanche del malecón". En Ante-proyecto de mejoramiento del puerto de Valparaiso. Santiago de Chile, Imprenta Cervantes, 1906. p.53. Collection Development Department. Widener library. HCL. Harvard University. sus dominios, bien innovadores para su época. Esto se ve plasmado en sus averiguaciones en la capital francesa con respecto a la posibilidad $\quad \mathrm{y}$ conveniencia de hacer en Chile investigaciones $\mathrm{y}$ experiencias sobre sustancias radioactivas. A su regreso a Chile, participó en diversos puestos en la Dirección de Obras $^{28}$, en la sección "Puentes, Caminos y Construcciones Hidráulicas". Un ejemplo de aquello son sus proposiciones para "el mejoramiento del puerto de Valparaíso" del 21 de septiembre de $1906^{29}$, que para aquellos años supusieron propuestas muy innovadoras por su radicalidad como lo muestra el "Proyecto de obras de mejora del puerto de Valparaiso embarcadero i ensanche del malecón". Colaboró además publicando el libro "el puerto de Valparaíso"30 y diversos artículos, principalmente en los Anales de la Ingeniería en Chile.

\footnotetext{
27 Edouard Collignon. Demande à l'effet d'être admis sans examen M Gonzalez. Ecole National des Ponts et Chaussées (ENPC). París 1889. Archives ENPC. Fonds complémentaires. 9582/9.

${ }^{28}$ Ernesto Greve. Historia de la ingeniería en Chile. IV. Santiago de Chile, Imprenta Universitaria, 1938. p.255.

${ }^{29}$ Post terremoto del 16 de agosto de 1906, magnitud 8.2. uno de los más destructivos de la ciudad

${ }^{30}$ Hijinio González. El puerto de Valparaíso. Santiago, Imprenta Universitaria, 1912.
} 


\section{Diseñando la Nación: Jóvenes becados por el gobierno a Europa, su contribución en la construcción del Chile de inicios del siglo XX}

En ámbito de la Arquitectura por su parte, don Manuel Aldunate estuvo en Europa desde 1845 a 1854, realizando estudios y trabajos encomendados por el Gobierno. A su regreso al país, desempeñó innumerables labores como las efectuadas entre 1857-1861 ${ }^{31}$ como arquitecto administrador del edificio del Congreso Nacional, fue el autor de los planos definitivos. En 1864 Ingresa al Cuerpo de Ingenieros Civiles, entre 1866-1874 primer chileno en el cargo de Arquitecto del Gobierno ${ }^{32}$. Como arquitecto fiscal colaboró con proyectos como el del parque Cousiño y del Cerro Santa Lucía, la casa consistorial de Valparaíso y de los Almacenes fiscales de aquel puerto, etc. En el libre ejercicio de su profesión levantó los planos y dirigió los trabajos de dos grandes edificios particulares, que en su tiempo fueron monumentos de arquitectura como el Palacio de don José Tomás Urmeneta en la calle Monjitas y el de la

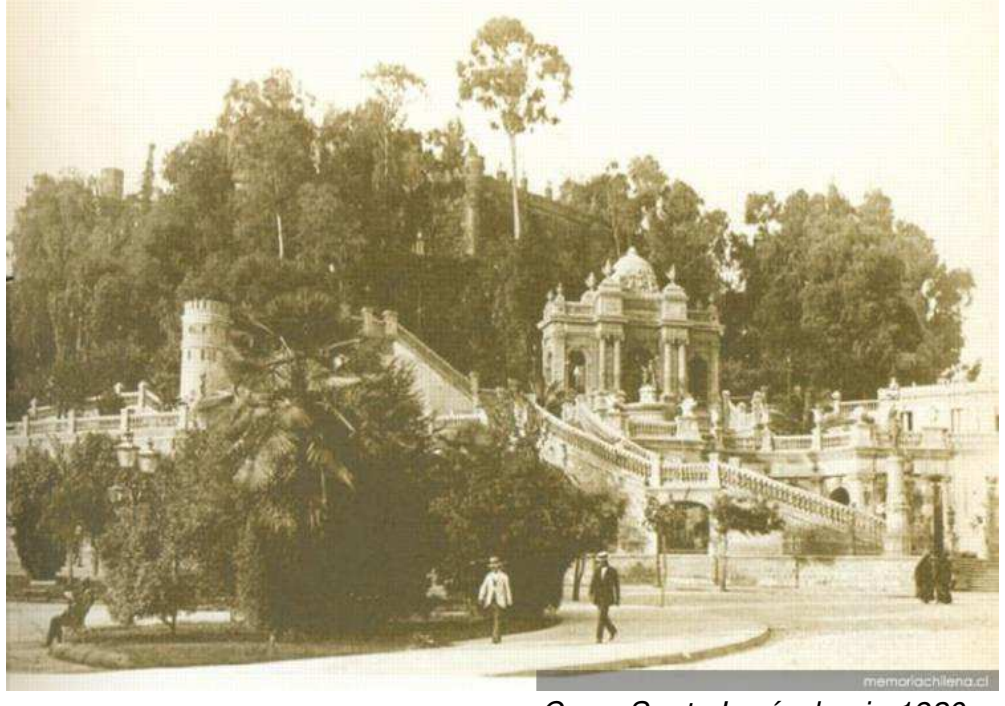
Cerro Santa Lucía, hacia 1920. Alhambra de don Claudio Vicuña, en la calle Compañía de Santiago de Chile.

Por su parte, de don Carlos Barroilhet ingeniero geógrafo, fue nombrado pensionado de gobierno de Chile el 16 de enero de 1888. A los 22 años de edad, viajó a Francia donde realizó estudios en arquitectura en la Academia Real de Bellas Artes de la ciudad de París. ${ }^{33} \mathrm{Su}$ aporte abarca muchos ámbitos, al ser un personaje muy activo socialmente. Así, de manera general, participó vivamente en la producción minera ${ }^{34}$, siendo presidente de la Asociación carbonífera, de la Cía. Minera Linquén, de la Cía. de gas de Valparaíso, entre otras. Además de ser socio de clubes de la elite de dicha ciudad y formar parte de la cámara Nacional de Comercio y participar en diversos Congresos. En lo que respecta a su vida profesional, Barroilhet trabajó tanto de arquitecto como de urbanista. Como arquitecto desarrolló proyectos como el edificio del Portal Edwards entre 1899-1901, el edificio del diario El Mercurio de Valparaíso en 1901, el nuevo Manicomio para la ciudad de Santiago entre los años

\footnotetext{
${ }^{31}$ Ernesto Greve. Historia de la ing..., Op. Cit., p. 214.

32 Como antecedente debemos saber que hasta el envío de Aldunate los arquitectos del Gobierno sólo habían sido extranjeros; Claude Francois Brunet de Baines (1848) o Lucien Ambroise Henault (1863).

33 L'Ecole Superieure d'Architecture. (ESAP) Certificat d'etude Carlos Barroilhet_Paris, 10 février 1890. ANC. Legación de Chile en Francia e Gran Bretaña 1819-1903, Vol. 238.

34 Fue uno de los técnicos que estudiaron a fondo el problema del Nitrato Chileno para combatir el Salitre sintético.
} 


\section{Tatiana Jiménez Bustos}

1894-1905. Este último lo llevó a formar parte de la junta de profesionales encargados por el Ministerio del Interior, para la concepción de la construcción hospitalaria del sur del país ${ }^{35}$. Como urbanista, este profesional fue parte de la comisión de estudio del plan completo de transformación de Viña del Mar, haciendo de este balneario un modelo en su género en el año 1927.

Finalmente en el área musical, contribuyeron al fortalecimiento del Conservatorio de Música fundado en 1850. Se destaca la figura de don Eliodoro Ortiz de Zárate pensionado en Italia en 1885 compositor de óperas, entre las cuales se destaca la obra titulada Lautaro, opera criolla que fuera estrenada en el Teatro Municipal de Santiago en 1902. Aurelio Silva por su parte, pensionado en París en 1886, había llegado a ser primer violinista en la ópera de dicha ciudad, a su regreso a Chile, fue nombrado primer violinista solista del Teatro municipal y fue destacado profesor del Conservatorio.

\section{Conclusión}

El análisis histórico del fenómeno de las becas gubernamentales de Chile hacia el extranjero hasta inicios del siglo $\mathrm{XX}$, se reconoce como un proceso muy temprano en relación a la región, basado en la antesala de un escenario de tranquilidad y orden publico en el país, que permitió la llegada de intelectuales, jurisconsultos y científicos venidos de Europa y América, quienes desde la década de 1830 influenciarían en un estado receptivo a legislar en pro de la realización de becas de estudios, con el propósito de contrarrestar el vacío de profesionales nacionales especializados. De igual forma, dicho fenómeno fue paulatino y no fue hasta 1888 que logró transformarse en un sistema oficial con la dictación de su primer reglamento.

Si bien, el auge económico (Ciclo del Salitre, a partir de 1883) fue crucial para la puesta en marcha de todo un engranaje de proyectos gubernamentales para convertir a Chile en una nación moderna, el sistema de pensiones en particular, desde mediados del siglo XIX, sería decisivo en la puesta en funcionamiento del proyecto de modernización del país. Dado que este sistema fue el que permitió la circulación de ideas europeas en el ámbito interno, no sólo como una moda traída por la elite nacional o como la realidad aportada por los extranjeros inmigrantes, sino más bien, como una política de Instrucción pública que lograría cambios más profundos en la nación. Más específicamente, fueron las ingenierías y las artes las que por casi veinte años se constituyeron en el germen de este sistema y el fundamento del mismo. Por ello, fue posible comprender la necesidad de la nación de ampliar y variar las becas al extranjero a otros ámbitos del conocimiento, como fue la medicina, la educación, la agricultura, la minería, etc., todo lo cual contribuyó a fortalecer la reciente República.

\footnotetext{
${ }^{35}$ Alexander Sievers. Médicos, instituciones y locura en Concepción, 1891-1929. Tesis de Maestría en Historia de Occidente. Chillán, Universidad del Biobio, 2013.
} 
Diseñando la Nación: Jóvenes becados por el gobierno a Europa, su
contribución en la construcción del Chile de inicios del siglo XX

Finalmente, la contribución de los becarios a su regreso al país fue crucial, abarcando de manera transversal la institucionalidad del país, desde lo publico a lo privado, desde lo cultural a lo científico, por nombrar algunos organismos: Ministerios de Interior, Justicia, Educación y Obras públicas; escuela de Bellas Artes, escuelas públicas, normales, liceos y universidades; sin dejar de lado la influencia provocada por los becarios en las diferentes expresiones artísticas, etc., valiosos aportes que Influenciaron tanto en el funcionamiento, como en la creación de diferentes instituciones y organismos claves en las políticas públicas a favor de la modernización de la nación.

\section{Bibliografía}

Alexander Sievers. Médicos, instituciones y locura en Concepción, 1891-1929. Tesis de Maestría en Historia de Occidente. Chillán, Universidad del Biobio, 2013.

Andrés Solimano. Capitalismo a la chilena: y la prosperidad de las élites. Santiago de Chile, Editorial Catalonia : Centro Internacional de Globalización y Desarrollo, 2013.

Benjamín Vicuña. La ciudad de las ciudades: correspondencias de Paris. Santiago de Chile, Sociedad Imprenta y Litografía Universo. 1905.

Chile. Decreto no4133 (1911). Reglamento sobre Becas en el extranjero. Diario Oficial de la República de Chile.

Chile. Decreto Reglamento de Pensionados en Europa. Santiago de Chile. Consejo de Instrucción Pública. 1888.

Chile, Congreso Nacional, Senado. Sesiones ordinarias de la cámara de Senadores de 1885. Santiago de Chile, La Cámara. 1885

Claudio Gay. Correspondencia de Claudio Gay. Santiago de Chile, Ediciones de la Biblioteca Nacional, 1962.

Edouard Collignon. Demande à l'effet d'être admis sans examen M Gonzalez. Ecole National des Ponts et Chaussées (ENPC). Paris 1889. Archives ENPC. Fonds complémentaires. 9582/9.

Ernesto Greve. Historia de la ingeniería en Chile. IV. Santiago de Chile, Imprenta Universitaria, 1938.

Eugenio Pereira. La arquitectura chilena en el siglo XIX. Anales de la Universidad de Chile. Serie verde, no. 2. Santiago: Universitaria. 1956.

Eva Cancino. Pensionados a París en el Siglo XIX: estudio comprensivo sobre el sistema de becas en Chile. Tesis de Licenciatura en Artes. 2011. 


\section{Tatiana Jiménez Bustos}

Universidad de Chile. Facultad de Arquitectura y Urbanismo. (FAU). 50 años de enseñanza de la arquitectura en la Universidad de Chile 1849 - 1999. Vol. 1. Santiago, 1999.

Francisco González. Aquellos años franceses 1870-1900: Chile en la huella de Paris. Santiago de Chile, Taurus, 2003.

Germán Riesco. Mensaje leído por S.E. el Presidente de la Repúblicas en la apertura de las sesiones ordinarias del Congreso Nacional. Santiago de Chile, Imprenta i Encuadernación Barcelona, 1905.

Hijinio Gonzalez. Ante-proyecto de mejoramiento del puerto de Valparaiso. Santiago de Chile, Imprenta Cervantes, 1906. Collection Development Department. Widener library, HCL. Harvard University.

Hijinio González. El puerto de Valparaíso. Santiago, Imprenta Universitaria, 1912.

José Miguel Blanco, "El envío de los pensionistas a Europa (al Sr. Ministro del Culto)". El Taller Ilustrado, periódico artístico y literario, № 59, Año II, Santiago, 1886.

L'Ecole Superieure d'Architecture. (ESAP) Certificat d'etude Carlos Barroilhet_Paris, 10 février 1890. ANC. Legación de Chile en Francia e Gran Bretaña 1819-1903, Vol. 238.

Macarena Ibarra. "El Centenario: ¿Un mito urbano?. Santiago de Chile 1887-1910”. Bicentenario. Revista de Historia de Chile y América. Vol. IV, №1. Santiago de Chile, 2005, pp.141-162.

Manuel Bulnes, "Discurso que el presidente de la República dirije al Congreso nacional. Año de 1844", en Documentos Parlamentarios. Discursos de apertura en las sesiones del Congreso, i, Memorias ministeriales correspondientes al Pmer. Quinquenio de la administración de Bulnes (1842-1846). Santiago, Imprenta del Ferrocarril, 1858, pp 213-217.

Manuel Bulnes. "Discurso que el presidente de la República en la apertura de las cámaras legislativas de 1847". Documentos Parlamentarios. Discursos de apertura correspondiente al segundo quinquenio de la administración de Bulnes. (1847-1851). T.III , Santiago, Imprenta del Ferrocarril, 1858, pp. 1-7. Manuel Montt. "Memoria que el Ministro de Estado en el departamento de Justicia Culto e Instrucción Pública presenta al Congreso Nacional. Año de 1841", en Documentos Parlamentarios. Discursos de apertura en las secciones del Congreso, i Memorias ministeriales correspondientes a la administración Prieto. (1831-1841). T.I. Santiago, Imprenta del Ferrocarril, 1858, pp. 225- 234.

Manuel Montt. Memoria presentada al Congreso Nacional en 1842 por el Ministro del 
Diseñando la Nación: Jóvenes becados por el gobierno a Europa, su
contribución en la construcción del Chile de inicios del siglo XX

Despacho de Justicia Culto e Instrucción Pública. Santiago, Imprenta y Litografia del Estado, 1842.

Manuel Montt. Correspondencia de dirigida al Encargado de Negocios del Gobierno de Chile cerca del de Francia. Santiago, 27 de Noviembre de 1845. En ANC, Legación de Chile en Francia y Gran Bretaña 1829-1877. Vol. 11.

Memoria sobre el 9ํ Congreso Internacional de Enseñanza Comercial, celebrado en Viena en Setiembre de 1910, presentada al señor Ministro de Instrucción Pública de Chile. Santiago, Imprenta Nacional, 1912, p. VIII.

Miguel Amunátegui. Don Manuel de Salas. Santiago de Chile, Imprenta Nacional, 1895.

Pablo Berrios. "Del taller a las aulas: la institución moderna del arte en Chile (17971910)." Santiago, Estudios de Arte. 2009.

Rafael Sagredo. "Geografía y nación. Claudio Gay y la primera representación cartográfica de Chile”. Estudios Geográficos. Vol. LXX, № 266, enero-junio, Madrid, 2009, pp. 231-267

Rafael Sagredo. Anales Del Instituto de Ingenieros de Chile: Ingeniería y Sociedad. [1a.] ed. Biblioteca Fundamentos de La Construcción de Chile 51. Santiago de Chile: Cámara Chilena de la Construcción: Pontificia Universidad Católica de Chile: Dirección de Bibliotecas Archivos y Museos (DIBAM), 2011.

Ramón Irarrázaval. Correspondencia dirigida al Encargado de Negocios de Chile en Francia. Santiago, 10 de Abril de 1844. En Archivo Nacional de Chile (ANC), Legación de Chile en Francia y Gran Bretaña 1829-1877. Vol. 11.

Rodrigo Gutiérrez. "El papel de las artes en la construcción de las identidades nacionales en Ibero-américa". Historia Mexicana, El Colegio de México. Vol. LIII, № 2, Oct. - Dec., México, 2003, pp. 341-390.

S/ Autor. El roto chileno de Virginio Arias. Negativo sobre vidrio. Catalogo Fotográfico Patrimonial, Colección Museo Histórico Nacional (MHN). PFB-2681, Chile. 1882.

Sol Serrano. "Universidad y nación: Chile en el siglo XIX". 1a. ed. Imagen de Chile. Santiago, Universitaria.1994.

Recibido: 01/11/2017

Evaluado: $15 / 12 / 2017$

Versión Final: 06/01/2018 